\title{
Mathematics AND Music ${ }^{1,2}$
}

\section{Personal Views on a Difficult Relationship}

\author{
Christian Krattenthaler (Universität Wien, Austria) ${ }^{3}$
}

\section{Preamble} $\langle$ Robert Schumann (1810-1856): “Aveu” from
Carnaval op. 9$\rangle^{4}$

Mathematics and music - stress on "AND" - question mark, this is our topic today. In order to enter the subject: when I am involved in a conversation, and the person with whom I am talking discovers that, on the one hand, I am professor of mathematics at the University of Vienna and, on the other hand, have been a concert pianist in a previous life, then it happens frequently that this person spontaneously exclaims:

\section{"Mathematics and Music - they are so close to each other!"}

To which I reply:

\section{"Is that really so?"}

What do I want to say? Frankly, I have always had big troubles with the topic "Mathematics AND Music", namely when mathematics and music are brought together, are set in relation to each other, or when one merely searches for connections between them. Yes, it is correct, tones and intervals obey strict mathematical rules, due to laws of physics; but does this establish a connection between mathematics and music? Yes, it is also true that Johann Sebastian Bach frequently wove numbers into his compositions. ${ }^{5}$ But is this mathematics? It

1 This is the English translation of the (slightly extended) script of a talk-performance that the author gave on May 16, 2013 in the math.space in the museums' quarter in Vienna. Since the author's performances of the piano pieces cannot be reproduced on printed paper, for each piece he provides a hint for an excellent performance.

2 The German original appeared in Int. Math. Nachr. 224 (2013), 29-60. The English translation appears here with the kind permission of the Austrian Mathematical Society.

3 I am deeply indebted to Theresia Eisenkölbl, who designed the computer presentation for this talk, parts of which have been incorporated into this article. I also thank Reinhard Winkler, for a careful reading of a rst version of the manuscript, and for numerous corrections and insightful comments. Last, but not least, I am extremely grateful to Tomack Gilmore for signicant and essential help with the English translation of the German original.

4 I did not find anything on YouTube which really convinces me. Tal-Haim Samnon's performance (http://www.youtube. com/watch? $v=$ EN2gUDaHqvo) matches the character, but drawls sometimes too much.

5 It is well documented, for instance (see, for example, Ludwig is also correct that compositions are often built in rather complex ways, that they have complicated forms. But is this mathematics in music? Conversely, if mathematics here I mean structure - becomes too dominant in music, as for example in serialism, where all parameters - pitch, rhythm, volume, etc. - are subject to strict rules, is the result still music?

Without further ado, I confess: I cannot see any direct, substantial connections between mathematics and music. In particular, I never have understood what mathematics has to do with, say, that touching confession, declaration of love ${ }^{6}$ from Robert Schumann - I suppose dedicated to his beloved Clara -, which I played at the beginning. If you had come to hear my answer to the question of the title of my talk: here it is! You could then safely go home. Of course, that would be too cheap, and, moreover, we would not have addressed a further question.

Let me rst take a step back. Not very long ago, a prominent visitor said to the Dean of the Fakultät für Mathematik of the University of Vienna:

\section{"I hear that you are chairing a department of pianists!"}

What did this visitor want to say? If you go through the list of members of the Fakultät für Mathematik - myself among them ${ }^{7}-$, then it is indeed remarkable how many of them are enthusiastic pianists. (The dean I refer to is one of them, by the way.) Moreover, there are others who play other instruments, there are those who are passionate choir singers, and there are others who do not play an instrument or sing but instead are devoted opera- and

Prautzsch, Die verborgene Symbolsprache Johann Sebastian Bachs, Band 1: Zeichen- und Zahlenalphabet der kirchenmusikalischen Werke. Merseburger, Kassel 2004), that Bach put numbers of psalm verses into his passions, at the places where these are cited. However, this remains concealed from a listener since this cannot be "extracted" by just listening; it can only be discovered and substantiated through a careful study of the score. This was an extraneous task that Bach chose to take upon himself.

The number that plays the biggest role in Bach's work is the number 14. In a sense, it is Bach's signature mark (in the same way as painters sign their paintings by putting their signature marks on them). In order to understand this, one has to observe that the number 14 is the sum of the positions of the letters $\mathrm{B}, \mathrm{A}, \mathrm{C}$, and $\mathrm{H}$ in our alphabet (to be precise, $2+1+3+8=14$ ). To mention an example, the number of pieces in the "Musicalisches Opfer" ("Musical Offering") is exactly 14 (if one counts correctly, of course, as one of the canons can be performed in two different ways).

6 "Confession", "declaration of love" - this is the meaning of the French word "aveu".

7 I was not dean then... 

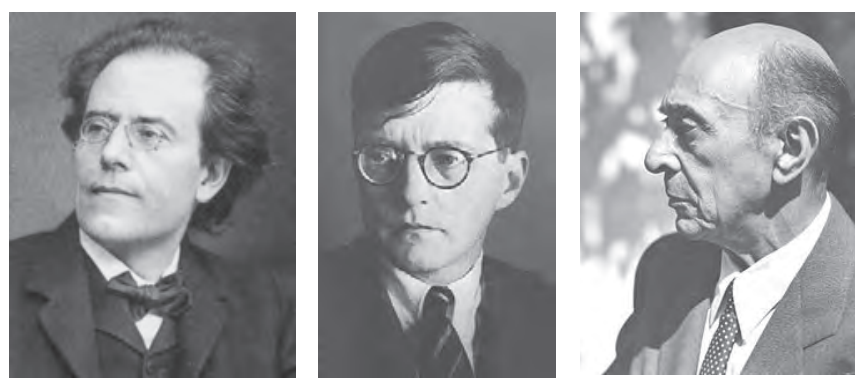

Figure 1. Gustav Mahler, Dmitry Shostakovich, Arnold Schönberg.

concert goers. In other words, the proportion of members of the Fakultät who have a great affinity for music is much higher than average. The same holds if one looks at other mathematics departments.

On the other hand, it is also surprising to see how many musicians also have an affinity for mathematics. A prominent example is the young pianist and composer Kit Armstrong, who, as is well known, studied with Alfred Brendel in London, but, on the side, also completed a mathematics degree at the Université "Pierre et Marie Curie" in Paris. is

Hence, the question that presents itself at this point

"Why are there so many mathematicians who also have a strong affinity for music, and why are there so many musicians who also have a strong affinity for mathematics?"

On a superficial level, we could phrase this question as follows:

"How do we imagine the typical mathematician - I mean, the typical sharp thinker, the typical intellectual?"

I would say that the portraits in Figure 1 match this image perfectly. You agree, don't you? We can cross-check:

"How do we imagine the typical musician - I mean, the typical sensitive artist?"

Exactly like the portraits in Figure 2, right?

For those who are not so familiar with the names "Wiles" and "Perelman", I should perhaps explain: Andrew Wiles, a British mathematician, is famous for having solved a 300 year old problem that goes by the name of "Fermat's Last Theorem". We shall hear more about this later. On the other hand, Grigori Perelman, a Russian - very eccentric - mathematician, is famous for the proof of a 100 year old conjecture of Henri Poincaré on four-dimensional geometry.

Before we attempt to answer the above question, we should perhaps first make precise what we are talking about. I am a mathematician, and in mathematics all objects must first be precisely defined before one can talk

\footnotetext{
8 http://en.wikipedia.org, as of 12 November 2016.

9 http://en.wikipedia.org, as of 12 November 2016.
}

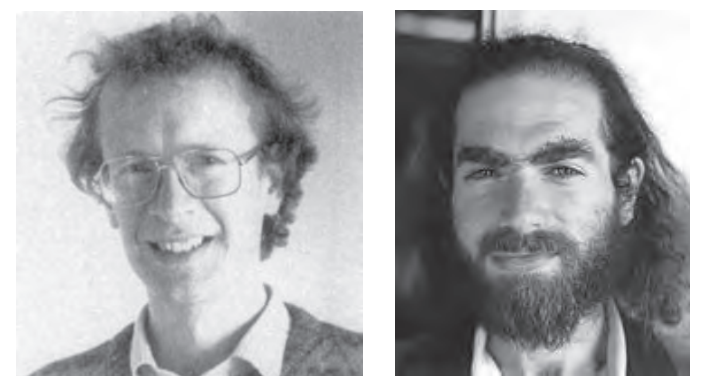

Figure 2. Andrew Wiles, Grigori Perelman.

about them. So, what is the definition of mathematics, what is the definition of music?

Music is ... arises ... comes about, when tones are produced ... when tones and noise are produced (I must not forget noise!). So, if these tones and noise sound, together...

I am sorry, I see that this does not really work. Let us try something easier! Mathematics - this is very simple:

Mathematics is ... art of calculation. Mathematics deals with numbers, ... geometric objects, ... more abstract objects - such as for instance algebraic structures and such - and ...

No, no, this makes no sense!

Actually, what I am doing here is completely stupid. Today one no longer racks one's brains, today one has Wikipedia! So, what does Wikipedia say about music? ${ }^{8}$

Music is an art form and cultural activity whose medium is sound and silence, which exist in time. The common elements of music are pitch (which governs melody and harmony), rhythm (and its associated concepts tempo, meter, and articulation), dynamics (loudness and softness), and the sonic qualities of timbre and texture (which are sometimes termed the "color" of a musical sound).

Well ... I would say: not completely wrong ... But I don't think that this is convincing. What does Wikipedia say about mathematics? ${ }^{9}$

Mathematics is the study of topics such as quantity (numbers), structure, space, and change.

Is this really mathematics?

What do I want to prove via this somewhat clumsy exercise? Of course, it is impossible to precisely say, to precisely define what music is, and it is equally impossible to precisely define what mathematics is (even if this may seem a little strange to the mathematical layman). Very good!

Nevertheless, I can precisely say what I mean when I talk here of music, when I talk here of mathematics. When I talk here of music, then I mean the art form music; art wants to express something, music wants to convey something to the listener with the help of tones and noise, it wants to give something to the audience to 


\begin{tabular}{|cccccc|}
\hline 1 & $\sqrt{2}$ & 12 & 8 & $\oint$ & \\
$5 \sum k^{2}$ & $16 \%$ & $0.123456789 \ldots$ & $\frac{3}{14}$ \\
8 & & $\pi$ & & $\frac{1+\sqrt{5}}{2}$ & \\
27 & 175560 & $\frac{2}{7}$ & 52954 \\
20.5 & e & 14 & & $99.999 \ldots$ \\
\hline
\end{tabular}

Figure 3.

take home. In order to make this absolutely clear: when I randomly press a few keys of a piano and then maybe bang the lid, then these were a few tones and one noise. This was not music; it did not say anything, and it did not want to say anything.

When I talk here of mathematics, I mean the science of mathematics; that is, we are talking of discovering new grounds, of solving mathematical problems, of investigating and studying mathematical phenomena, and of revealing the structure and connections lurking behind. In order to completely clarify this point: when I randomly type mathematical numbers and symbols on the page (like in Figure 3), this is not mathematics.

I can now precisely explain my difficulties with the topic "Mathematics AND Music". When Bach weaves numbers into his compositions, then these are numbers, this is not mathematics. Moreover, these numbers do nothing for the message of the work as it is transmitted to the audience. When compositions take on complex forms, then, from the point of view of the science of mathematics, this is either trivial or completely without interest. When mathematics - structure - starts to dominate music - when, in the extreme case, we program a computer to produce ("compose") tones and then eagerly await the result, then out will come tones but no music. This will convey nothing. What music shall do for mathematics, is entirely unclear anyway. ${ }^{10}$ Thus for me the interesting question is not that of the connections between mathematics and music, but rather:

${ }^{10}$ If one ignores that the reconstruction and analysis of sound documents pose very interesting and challenging mathematical problems; see for example: A. Boggess and F. Narcowich, A first course in wavelets with Fourier analysis, second edition, John Wiley \& Sons, Inc., 2009. However, also here we are not talking of a true substantial relation or connection between mathematics and music: the substance lies entirely on the side of mathematics, music as an art form is not affected here. In this context, one could also think of some colleagues who have apparently better ideas if they have music playing on the side. I do not belong to these: bad music is annoying, and good music - it enthrals me, I have to listen to it, I can't think about mathematics at the same time. In any case, this leads us somewhat off-course...

Closest to a true connection between mathematics and music is research as done, for example, by Gerhard Widmer (even if his work rather belongs to Artificial Intelligence; see http://
"Why are there so many mathematicians who also have a strong affinity for music, and why are there so many musicians who also have a strong affinity for mathematics?"

To give it away, the thesis which I shall defend here is:

Both Mathematics AND Music are food for the soul AND the brain.

Maybe there is a region in our brain which resonates responds to - particularly when emotion and intellect come together, form a symbiosis. Maybe this provides the explanation for the phenomenon which is touched upon in the above question. In the following, I shall attempt to substantiate this thesis.

\section{Soul in music}

You will say: "This is like carrying coals to Newcastle! Of course, emotion plays an enormously important role in music." You are obviously completely right. Nevertheless, I want to say a few words about this, because not only can it have many different facets, but also it gives me the opportunity to play the piano a little...

You remember: music wants to express something, wants to transmit something to the audience. This may be many different things. For example, music may simply spread good cheer...

〈Scott Joplin (1867/1868?-1917): Maple Leaf Rag (beginning) $\rangle^{11}$

or bad...

\section{$\langle$ Robert Schumann (1810-1856): Pantalon et} Colombine (beginning) from Carnaval op. 9$\rangle^{12}$

Music can be heartbreakingly sad...

〈Franz Schubert (1797-1828): Andantino (beginning) from the Sonata in A major, D 959$\rangle^{13}$

or transcendentally joyful...

www.cp.jku.at/people/widmer/), who, with the help of mathematical models, investigates specialities and peculiarities of interpretations of pianists, or, on the other hand, tries to "teach" computers how to "interpret" musical scores agogically - varying the tempo as the piece moves along - "correctly" - on a piano. He is however well aware of the limits of such studies and experiments, even if it is not clear where these lie exactly.

${ }^{11}$ Absolutely worth listening to is the pianola roll recording played by Scott Joplin himself: http://www.youtube.com/ watch? $=$ pMAtL7n_-rc.

12 Arturo Benedetti Michelangeli knows how to perfectly portray a squabbling couple (who then reconcile, only to begin squabbling again, etc.): http: //www.youtube.com/ watch?v=LgpDYQcmZB4.

13 The "measure of all things" concerning Franz Schubert's work for piano is, without any doubt, Alfred Brendel: http:// www.youtube.com/watch?v=Il6-1ZYDpqY. 


\section{$\langle$ Franz Schubert (1797-1828): Impromptu A flat major, D 899, Nr. 4 (end) $\rangle^{14}$}

Music may radiate elegance, and what better accomplishes this than a waltz by Chopin?

\section{〈Frédéric Chopin (1810-1849): Grande Valse Brillante E flat major, op. 18 (beginning) $\rangle^{15}$}

We come to humour in music. This is an entire topic in itself. The grand master of humour in music was without any doubt Joseph Haydn. All of you know his most famous joke: that sudden fortissimo chord from the entire orchestra in his "Surprise Symphony". There, as you all will recall, the second movement begins with the most trivial theme that one can imagine, and, as if that were not enough, this theme is repeated! It is understandable that one nods off a bit at this point, before, suddenly, the orchestra roars off completely without warning. Today, we are used to quite a bit, however at the time the effect was certainly enormous ... I want to draw your attention to a little detail that is not that obvious at first sight. Joseph Haydn grew up in deepest Lower Austria, later living in Vienna and in Eisenstadt in Burgenland. ${ }^{16}$ This joke, however, represents ${ }^{17}$ typical British humour: it is told "with a straight face". After that fortissimo chord, one constantly - and nervously - awaits further consequences as the movement continues (for instance, in the form of further shock effects...). But, no: nothing happens at all, the music continues as if nothing had occurred...

Normally, however, humour in music is of a finer nature. Usually, the expectations of the listener are led astray, and it is in this manner that humourous effects are produced. A nice example for this is the first of the Humoresken by Max Reger. This piece has quite a graceful main theme, which however cannot develop as it would like. This main theme dominates two short sections at the beginning and at the end that frame a middle section, which considers itself as slightly too important, and thereby also creates an amusing impression.

\section{〈Max Reger (1873-1916): Humoreske D major, op. $20 / 1\rangle^{18}$}

I have a final point to offer: Tour de Force! I think you know: the thunderous hammering of keys in the Liszt Sonata, for example...

\section{$\langle\text { Franz Liszt (1811-1886): Sonata b minor (excerpt) }\rangle^{19}$}

If you listened attentively then you will have observed that I studiously avoided one word in particular: the word

${ }^{14}$ Alfred Brendel: http://www.youtube.com/watch?v=V0z7m UV5rSc

${ }^{15}$ Inimitable in his elegant, natural style of playing is Arthur Rubinstein: http://www.youtube.com/watch?v=laSh3D_77ZM, even if he does not take "brillante" too strictly...

${ }^{16}$ A rural region of Austria to the south-east of Vienna.

${ }^{17}$ It is fitting that that symphony is one that Haydn wrote for London. "nice" (as well as the word "beautiful"). On this point, I shall digress a little.

Not long ago, I attended a performance of the opera "Mathis der Maler" by Paul Hindemith. The opera is finished, the applause has ceased and then I hear one person saying to her neighbour: "Very nice!" I was quite taken aback. What was that? One must know that "Mathis der Maler" is set during the peasants' wars in Germany. This was a very dark epoch. The peasants revolted against the abuses that were visited upon them by their landlords, and the latter crushed this revolt mercilessly. During the opera, one of the leaders of the peasants' movement is cruelly slaughtered openly on-stage. At the heart of the story lies the conflict of conscience of the artist Mathis over how to behave during these times. Should he continue to work on his canvases and sculptures, or should he "engage himself in politics"? Finally, he joins the peasants' revolt and, of course, achieves nothing. At the end of the opera, a voice announces that the artist should stick to his art, but this is not really convincing. Clearly, Paul Hindemith projects his own personal conflict over how to behave as an artist in the face of the Nazi regime into this opera. The music reflects all of this. It is disturbing, very intelligent, but one cannot characterise it as "nice." Bluntly: there are very few pure major chords in this opera...

I want to drive this particular point home:

\section{Music does not want to be nice!}

What I mean is: music wants to say something, wants to express something to a listener. This may be accompanied by beauty, but then beauty is not an end in itself, it is always a means to an end. But it need not be accompanied by beauty. "Sacre de Printemps" by Igor Stravinsky is eruptive, explosive, but it is not "nice" or "beautiful". The last movement of the "Great Sonata for the Hammerklavier" in B flat major, op. 106, by Ludwig van Beethoven, the movement containing the fugue, is many things - grand, bold, unprecedented -, but it is certainly not "nice" or "beautiful". In fact, one has to wait for a hundred years until again a piece is written which contains similar harmonic abrasiveness. Even in the work of Johann Sebastian Bach one cannot call many of his compositions "nice", since frequently consistent progression of voices is more important than "nicely sounding" harmonies. When saying this, I have in mind some of the canons in the "Goldberg Variations", each of which has its distinctive character, but which are not always "nice".

Hence, when, after a performance of "Mathis der Maler", I hear: "Very nice!", then I am strongly reminded of the celebrated standard phrase of the "alte Kaiser"

\footnotetext{
${ }^{18}$ Marc-André Hamelin does quite well in http://www.youtube. $\mathrm{com} /$ watch? $\mathrm{v}=$ ba5js057WGM.

${ }^{19}$ I like a recording from the Salzburg Festival, of which I possess a CD and in which Emil Gilels plays extraordinarily. On YouTube there exists a recording in three parts that is not quite as good: http://www.youtube.com/watch? $=7$ yhGSrn3idI, http:// www.youtube.com/watch?v=gyQ-MnjRvsE, http://www.youtube.com/watch?v=EKUAFRosm 48 .
} 
Franz Joseph, ${ }^{20}$ who used to apply it whenever he was confronted with cultural intrusions:

\section{“Es war sehr schön, es hat mich sehr gefreut!”21}

For somebody, who apparently did not have any affinity for culture, this was seemingly the best he could say about it...

Let us return to the actual subject of this essay.

\section{Soul in mathematics}

For non-mathematicians, this will look like a pretty difficult topic. After all, we have all learned in high school that mathematics is a dust-dry, abstract matter, which is about applying recipes that have been known for centuries to more or less intelligent exercises, and hoping that one has selected the correct recipe... (For the vindication of my mathematics teacher, I must say that I did not learn this in high school.) Anyhow, I believe that on the topic of "soul in mathematics" we should hand over to the earlier mentioned Andrew Wiles.

As I have already said, Wiles is famous for having proved "Fermat's Last Theorem." The statement of this theorem can be understood by any high school student, and I shall therefore present it here.

Theorem (Wiles, Taylor 1995). (Fermat's Last Theorem) Let $n$ be a natural number which is at least 3. Then there are no natural numbers ${ }^{22} x ; y ; z$ such that

$$
x^{n}+y^{n}=z^{n}
$$

Pierre de Fermat scribbled this assertion over 300 years ago into the margin of a page of an exemplary of Diophantos' book "Arithmetica". ${ }^{23}$ In order to increase the suspense, he also added that he has found a "truly wonderful" proof of this, but that the page margin was not wide enough to hold this proof. Since then, many very clever people racked their brains about this problem. As a matter of fact, much of number theory ignited itself on exactly this problem. However, for over 300 years nobody could find a proof of Fermat's assertion. We may therefore safely assume that Fermat did not really have a proof, in any case not something that we would accept as a proof nowadays. It was a big sensation when Andrew Wiles announced at the end of a series of lectures that he gave at the Isaac Newton Institute in Cambridge in 1993 that he had found a proof. Now, in mathematics it is not sufficient to just announce that one has found the proof of a theorem (as Fermat did). The proof must be written

\footnotetext{
${ }^{20}$ Franz Joseph I. (1830-1916), Emperor of Austria 1848-1916.

${ }^{21}$ It was very nice! I enjoyed it very much!

${ }^{22}$ In order to avoid any misunderstanding, when I speak of "natural" numbers, I mean the numbers $1,2,3, \ldots$, which corresponds to the original meaning of the word "natural". Nowadays, unfortunately, one learns in school that the "natural numbers" consist of the numbers $0,1,2, \ldots$ This may indeed be handy in some situations but it is simply a perversion of the word "natural", since 0 is without any doubt not a natural number.
}

down in order to let others read and check it - Wiles did that; the result was an article of 200 pages, which itself was based on previous work by numerous other authors - , and the writeup must be submitted to a scientific journal for publication - Wiles also did that -, after which referees carefully verify this proof. During this process, it was discovered after a short while that Wiles' proof contained a gap that he was unable to fill. It needed another two years until Wiles, in joint work with his former student Richard Taylor, succeeded in repairing this hole. In a BBC documentary, ${ }^{24}$ Andrew Wiles says the following about the moment when he realised that now all difficulties are overcome:

[Wiles is visibly deeply moved and speaks haltingly] When I was sitting here, at this desk - it was a Monday morning, September 19 - and I was trying convincing myself that it did not work, seeing exactly what the problem was, when suddenly, totally unexpectedly, I had this incredible revelation. I realised [that] what was holding me up was exactly what would resolve the problem that I had in my Iwasawa theory attempt three years earlier.

It was-. it was the most - the most important moment of my working life ... [At this point, Wiles is finally no longer able to continue; the scene is faded out.] It was so indescribably beautiful, it was so simple and so elegant ... - and I just stared in disbelief for $20 \mathrm{~min}$ utes .... - then during the day I walked to our department, I keep coming back to my desk, looking to see, it was still there, it was still there...

Impressive, isn't it? Contrary to widespread perception, mathematics seems to be a highly emotional activity. I noticed various emotions, including everything from "heartbreakingly sad" - at the point when the construction of the proof was in danger of collapsing - up to "transcendently joyful" - at the point when Wiles realised that he has now mastered all difficulties. You may argue that Wiles is so moved because it was him who first solved this famous problem. This is certainly a component. However, it falls short of the full truth. Wiles also says: "This was so indescribably beautiful, so elegant!". Mathematics must have other qualities than just being "dust-dry" and "abstract". We should hence discuss some of these qualities in greater depth.

As I have already said, once a mathematician has proved a fantastic theorem, then this proof must be written down and be submitted for publication, whereupon the corresponding article is examined. The referees do

${ }^{23}$ The background/context of this assertion is the sharp contrast to the situation for $n=2$ : in that case, there are infinitely many solutions to the equation $x^{2}+y^{2}=z^{2}$ in the natural numbers $x, y, z$, which can be precisely characterised and which are known as "Pythagorean triples". Two of these we know from high school: $3^{2}+4^{2}=5^{2}$ and $5^{2}+12^{2}=13^{2}$.

${ }^{24}$ The complete documentary can be seen at http://www.youtube.com/watch?v=7FnXgprKgSE. The cited passage appears roughly 5 minutes before the end. The very beginning of the documentary is also remarkable... 
not only judge correctness of proofs but also the other qualities of the article. A standard phrase that a referee might use to show that they like the article is:

\section{"This is a very nice paper!"}

In view of the previous digression on "beauty" of music: funny, isn't it? Mathematicians also don't know anything better than saying "nice"... However, if the referee provides a sound opinion then they would also tell more specifically what they like about the article. Then we may sometimes read:

\section{"This is a very elegant proof!"}

What is an "elegant proof"? In other words, what is a "mathematical waltz by Chopin"? Usually, we are talking about the situation where - in a proof - the mathematician is facing a seemingly insurmountable obstacle. With the help of a relatively simple, but not at all obvious, idea, the mathematician succeeds however to - elegantly - circumnavigate this obstacle. I shall try to give an example, the theorem, known to everybody, that there are infinitely many prime numbers.

\section{Theorem. There are infinitely many prime numbers.}

Proof. If one looks at this assertion, what would we have to do in order to prove it? It seems that we would have to construct infinitely many primes. We would do even better if we could find a formula which gives us all prime numbers (or at least infinitely many). This is pretty hopeless. ${ }^{25}$

However, there is an - elegant - way around this. Let us suppose that there are only finitely many prime numbers. If, under this assumption, we succeed in deriving a contradiction, then our original assumption must have been wrong. Thus, we would have shown that there are indeed infinitely many prime numbers.

So, let us suppose that there are only finitely many prime numbers; say, 2, 3, 5, 7, 11, 13, .., 1031 .

We now consider

$$
2 \cdot 3 \cdot 5 \cdot 7 \cdot 11 \cdot 13 \cdot \ldots \cdot 1031+1:
$$

This (huge) number can be decomposed into a product of prime factors. Each of these prime factors must, on

\footnotetext{
${ }^{25}$ Mathematics offers plenty of incredibly fascinating, respectively absurd, facts - depending on which point of view one is willing to take... the Russian mathematician Yuri Matiyasevich proved that there exist polynomials in several variables whose positive values - if the variables are specialised to concrete natural numbers - run through all prime numbers; see Dokl. Akad. Nauk SSSR 196 (1971), 770-773; Soviet Math. Dokl. 12 (1971), 249-254. Such polynomials have indeed been constructed explicitly. Not only do they have the "annoying" property that they attain (some) negative values, but in particular this property is satisfied most of the time... Hence, they are today just a curiosity, since, aside from their existence, they do not seem to be good for anything.
}

the one hand, divide this number and, on the other hand, must appear among the prime numbers $2,3,5,7,11,13, \ldots$, 1031. (Remember that we assumed that these are all the prime numbers!) Let $p$ be such a prime factor. $p$ cannot equal 2 since the above number is visibly an odd number. But $p$ can also not equal 3 since 3 does not divide a number of the form $3 X+1$, of which the above number is an example. For an analogous reason, the prime factor cannot equal $5, \ldots$, and it cannot equal 1031. Hence, this cannot have been all the prime numbers.

Now you will object: "This is all fine, however this is not a rigorous - valid in generality - mathematical proof." After all, 1031 is just one special prime number. You are right, but the rigorous proof looks exactly the same. The only thing that needs to be done is to replace $2,3,5, \ldots$, 1031 by symbols: $p_{1}, p_{2}, p_{3}, \ldots, p_{n}$.

Proof. Let us suppose that there are only finitely many prime numbers, say, $p_{1}, p_{2}, p_{3}, p_{4}, p_{5}, p_{6}, \ldots, p_{n}$.

We now consider

$$
p_{1} \cdot p_{2} \cdot p_{3} \cdot p_{4} \cdot p_{5} \cdot p_{6} \cdot \ldots \cdot p_{n}+1:
$$

This (huge) number can be decomposed into a product of prime factors. Each of these prime factors must, on the one hand, divide this number and, on the other hand, must appear among the prime numbers $p_{1}, p_{2}$, $\ldots, p_{n}$. (Remember that we assumed that these are all the prime numbers!) Let $p$ be such a prime factor. $p$ cannot equal $p_{1}$ since $p_{1}$ does not divide the number above. But $p$ can also not equal $p_{2}$ since $p_{2}$ does not divide the above number. For the same reason, the prime factor cannot equal $p_{3}, \ldots$, and $p_{n}$. Hence, this cannot have been all the prime numbers.

We come to Humour in Mathematics. Can there really be humour, or indeed jokes, in mathematics? Well, this must be the case, since sometimes we may read in a reviewer's report:

\section{"This is a funny construction!"}

How does humour appear in mathematics? Humour in mathematics is - as in music - normally of a finer nature. Also here, the expectations of the reader of a proof are led astray before, suddenly, a little detail surfaces, which we had not noticed earlier, but it is exactly this little detail which is the last (but decisive!) little brick that is needed to complete the argument. At this point, a mathematician must smile (how could (s)he have overlooked this?), and it delights her/his soul.

I shall try once more to give an example, this time extracted from the work of the celebrated Indian mathematician Srinivasa Ramanujan (see Figure 4). Born in 1887 in the vicinity of Madras (today Chennai), Ramanujan had a very modest upbringing. He had only a basic school education, but had always been interested in mathematics and mathematical problems. After finishing school, he worked as a clerk in the Madras Port trust, but in his leisure time 

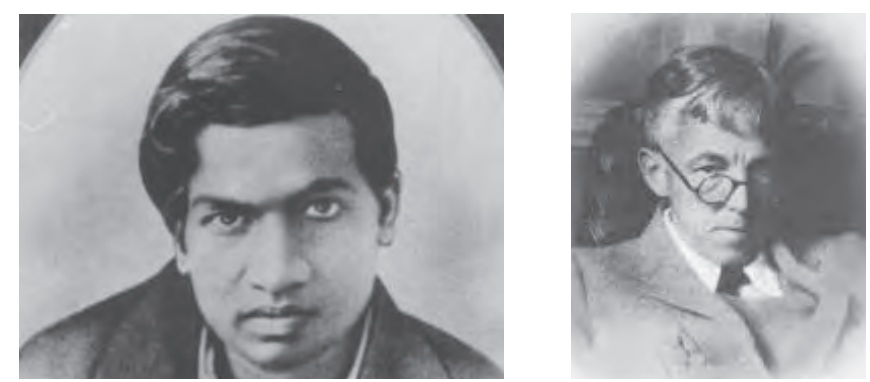

Figure 4. Srinivasa Ramanujan, Godfrey Harold Hardy.

he constantly worked on mathematical problems. At the age of 25 , he sent his mathematical results to eminent mathematicians of the time. One of them, Godfrey Harold Hardy, Professor at the University of Cambridge, indeed read Ramanujan's letter and recognised the genius of the unknown author. He invited Ramanujan to come to Cambridge, and to study and work with him. Benefactors in India succeeded in collecting the money necessary to finance the journey to England, thus Ramanujan spent some years at the University of Cambridge. During this time, he wrote several very famous articles, often in collaboration with Hardy. Unfortunately, Ramanujan could not bear the British climate (as well as British nutrition...) and was frequently ill; within a year of returning to India he passed away at the age of only 32 years.

One of the objects that were very dear to Ramanujan in his mathematical work was (integer) partitions. A partition of a number $n$ is the representation of this number as a sum of other natural numbers, where the summands are arranged in (weakly) increasing order. For $n=1$, there is exactly one such representation, namely,

1

For $n=2$, there are two, namely,

$$
2, \quad 1+1
$$

For $n=3$, there are three partitions,

$$
3,1+2,1+1+1
$$

For $n=4$, we already have five,

$4, \quad 1+3, \quad 2+2, \quad 1+1+2, \quad 1+1+1+1$,

and, for $n=5$, we have

$$
\begin{aligned}
& 5, \quad 1+4, \quad 2+3, \quad 1+1+3, \quad 1+2+2, \quad 1+1+1+2, \\
& 1+1+1+1+1 \text {. }
\end{aligned}
$$

Let $p(n)$ denote the number of partitions of $n$. Percy Alexander MacMahon, Major of the British army and

${ }^{26}$ And he did this without making a single mistake! Even if he did not accomplish this by listing all partitions of numbers up to 200 , but rather by using a recurrence relation due to Euler, this constitutes - at a time that knew of no "computing machines" except paper and pencil - an extraordinary achievement!

${ }^{27}$ Ramanujan made similar observations for the prime numbers 7 and 11. Together with the theorem discussed in the text, these founded the research area of "partition congruences", which has witnessed important breakthroughs during the past few years; see page 1525 in the survey article "Srini- at the same time an eminent mathematician then, had calculated the numbers $p(n)$ up to $n=200 .{ }^{26}$ The first few numbers $p(n)$ are shown here:

$$
\begin{aligned}
& p(1)=1 \quad p(2)=2, \quad p(3)=3, \quad p(4)=5, \quad p(5)=7 \\
& p(6)=11 \quad p(7)=15, \quad p(8)=22, \quad p(9)=30, \quad p(10)=42 \\
& p(11)=56 \quad p(12)=77, \quad p(13)=101, \quad p(14)=135, \quad p(15)=176 \\
& p(16)=231 \quad p(17)=297, \quad p(18)=385, \quad p(19)=490, \quad p(20)=627
\end{aligned}
$$

Ramanujan studied MacMahon's tables intensively, and made remarkable observations. One of these is made explicit in the theorem below. It says that every fifth partition number is divisible by 5 ; see the bold face entries in the above table. ${ }^{27}$

Theorem ("Ramanujan's most beautiful theorem"1919). $p(5 n+4)$ is always divisible by 5 .

This theorem acquired the byname "Ramanujan's most beautiful theorem", ${ }^{28}$ since it is so simple and elegant to formulate, and at the same time it is so unexpected. Moreover, Ramanujan himself found a proof for it. Here, I want to discuss a proof taken from a paper of Hirschhorn and Hunt, ${ }^{29}$ which is very much in the spirit of Ramanujan. I am fully aware that the following is (mathematically) more demanding than everything else we have discussed so far. If you should not understand everything (or understand almost nothing...), this is fine. My point here is to indicate what "humour" may mean in mathematics.

The proof is based on an old result of Leonhard Euler. It says that the power series, in which the numbers $p(n)$ appear as coefficients, can be written in terms of an infinite product.

\section{Theorem (Euler). We have}

$$
\begin{aligned}
1+p(1) q+p(2) q^{2} & +p(3) q^{3}+p(4) q^{4}+\cdots \\
& =\frac{1}{(1-q)\left(1-q^{2}\right)\left(1-q^{3}\right)\left(1-q^{4}\right) \cdots} .
\end{aligned}
$$

Proof. It is quite possible that you feel uneasy when looking at these infinite sums and products. You may ask: "Does this really converge?"30 But this is the wrong question! The above expressions should be regarded as formal expressions, which are added, multiplied, etc., naively. ${ }^{31}$

Let us adopt this formal point of view. Then, Euler's formula can be proved in the following way. The product on the right side consists throughout of factors of the

vasa Ramanujan: Going Strong at 125, Part I", that appeared in the Notices of the American Mathematical Society, vol. 59, Nr. 11, 2012, edited by Krishnaswami Alladi, and is available at http://www.ams.org/notices/201211/rtx121101522p.pdf.

${ }^{28}$ Strictly speaking, it is the identity $(*)$ below, which Hardy selected as "Ramanujan's most beautiful identity."

${ }^{29}$ J. reine angew. Math. 326 (1981), 1-17.

${ }^{30}$ It does for $|q|<1$.

${ }^{31}$ All this can be made rigorous by the theory of so-called formal power series. 
form $\frac{1}{1-q^{k}}$. In high school, we learned that the infinite geometric series can be summed: ${ }^{32}$

$$
1+Q+Q^{2}+Q^{3}+Q^{4}+\cdots=\frac{1}{1-Q}
$$

We may apply this summation formula to each of the factors (so-to-speak: reading it backwards):

$$
\begin{aligned}
\frac{1}{(1-q)\left(1-q^{2}\right)\left(1-q^{3}\right)\left(1-q^{4}\right) \cdots} \\
=\frac{1}{1-q} \cdot \frac{1}{1-q^{2}} \cdot \frac{1}{1-q^{3}} \cdot \frac{1}{1-q^{4}} \cdots \\
=\left(1+q^{1}+q^{1+1}+q^{1+1+1}+\cdots\right) \\
\quad \cdot\left(1+q^{2}+q^{2+2}+q^{2+2+2}+\cdots\right) \\
\quad \cdot\left(1+q^{3}+q^{3+3}+q^{3+3+3}+\cdots\right) \cdots .
\end{aligned}
$$

Now we must imagine what happens if we expand this last product. Each term in the result arises by selecting one term from each factor, and by multiplying these terms. For example, if we select the term $q^{1+1}$ from the first factor, the term $q^{2+2+2}$ from the second, the term $q^{3}$ from the third factor and the term 1 from all remaining factors, then we obtain

$$
q^{1+1+2+2+2+3}
$$

upon multiplication of these terms. Now it costs just a few moments to convince oneself that the exponents of the expressions one obtains in this manner run through all partitions. Thus, the above product is indeed equal to the lefthand side of Euler's theorem.

We are now in the position to embark on the proof of Ramanujan's "most beautiful theorem".

Proof of Ramanujan's most beautiful theorem. In order to have a compact notation, ${ }^{33}$ we abbreviate the product $(1-q)\left(1-q^{2}\right)\left(1-q^{3}\right)\left(1-q^{4}\right)$ by $(q ; q)_{\infty}$. More generally, we write

$$
(\alpha ; q)_{\infty}=(1-\alpha)(1-\alpha q)\left(1-\alpha q^{2}\right)\left(1-\alpha q^{3}\right) \cdots
$$

The proof is based on several auxiliary results. These auxiliary results can be derived by means of elementary (but tricky) manipulations of power series and by the use of Jacobi's triple product formula

$$
\sum_{n=-\infty}^{\infty}(-1)^{n} q^{n(n-1) / 2} x^{n}=(q ; q)_{\infty}(x ; q)_{\infty}(q / x ; q)_{\infty} .
$$

It would however go definitely beyond the scope of this discussion to explain this in detail here.

\section{Lemma. Let $\omega^{5}=1, \omega \neq 1$. Then}

$(q ; q)_{\infty}(\omega q ; \omega q)_{\infty}\left(\omega^{2} q ; \omega^{2} q\right)_{\infty}\left(\omega^{3} q ; \omega^{3} q\right)_{\infty}\left(\omega^{4} q ; \omega^{4} q\right)_{\infty}$

$$
=\frac{\left(q^{5} ; q^{5}\right)_{\infty}^{6}}{\left(q^{25} ; q^{25}\right)_{\infty}} \text {. }
$$

\footnotetext{
32 The formula is also valid in the theory of formal power series.

${ }^{33}$ Ramanujan did not know this notation, and did not use any other short notation. Consequently, to read notes of Ramanujan constitutes a certain challenge.
}

This lemma entails two further lemmas.

Lemma. We have

$$
\frac{(q ; q)_{\infty}}{q\left(q^{25} ; q^{25}\right)_{\infty}}=q^{-1} R-1-q R^{-1},
$$

where $R$ is a power series in $q^{5} \cdot{ }^{34}$

\section{Lemma. We have}

$$
q^{-5} R^{5}-11-q^{5} R^{-5}=\frac{\left(q^{5} ; q^{5}\right)_{\infty}^{6}}{q^{5}\left(q^{25} ; q^{25}\right)_{\infty}^{6}} .
$$

Now, we may combine these lemmas ${ }^{35}$ in order to find the following expression for the so-called "generating function" for the partition numbers:

$$
\begin{aligned}
& 1+p(1) q+p(2) q^{2}+p(3) q^{3}+p(4) q^{4}+p(5) q^{5} \\
& +p(6) q^{6}+p(7) q^{7}+p(8) q^{8}+p(9) q^{9}+p(10) q^{10} \\
& \quad+p(11) q^{11}+p(12) q^{12}+p(13) q^{13}+p(14) q^{14}+\cdots \\
& =\boldsymbol{q}^{4} \frac{\left(q^{25} ; q^{25}\right)_{\infty}^{5}}{\left(q^{5} ; q^{5}\right)_{\infty}^{6}} \cdot\left(q^{-4} R^{4}+q^{-3} R^{3}+2 q^{-2} R^{2}+3 q^{-1} R+\mathbf{5}\right. \\
& \left.\quad-3 q R^{-1}+2 q^{2} R^{-2}-q^{3} R^{-3}+q^{4} R^{-4}\right) .
\end{aligned}
$$

By this time, we have certainly lost sight of our overall goal. Why do we write such a complicated expression for the generating function of the partition numbers? What did we actually want to prove? It is at this point that the punch line reveals itself! We are actually only interested in the partition numbers $p(4), p(9), p(14), p(19)$, etc., that is, in

$$
p(4) q^{4}+p(9) q^{9}+p(14) q^{14}+p(19) q^{19}+\cdots
$$

Let us look at the right-hand side of the above complicated expression: there we see the series $R$, which according to the lemma contains only powers of $q^{5}$. Also, the products $\left(q^{5} ; q^{5}\right)_{\infty}$ and $\left(q^{25} ; q^{25}\right)_{\infty}$ consist only of powers of $q^{5}$. At the front of this expression, there is the factor $q^{4}$. So, inside the big parentheses, the only terms that are of interest for us are powers of $q^{5}$; everything else can be neglected. However, if one actually looks inside carefully (the reader should recall that the series $R$ only contains powers of $q^{5}$ !) then the only term that is relevant is the lonely 5 ! In other words, from the horrendous formula above (the reader should concentrate on the terms in bold face), one can immediately extract that:

$$
p(4) q^{4}+p(9) q^{9}+p(14) q^{14}+\cdots=q^{4} \frac{\left(q^{25} ; q^{25}\right)_{\infty}^{5}}{\left(q^{5} ; q^{5}\right)_{\infty}^{6}} \times 5 .
$$

The point here is: on the right-hand side everything gets multiplied by 5 ! Consequently, all coefficients on the left-hand side - that is, $p(4), p(9), p(14), p(19)$, etc.

\footnotetext{
${ }^{34}$ There also exists an explicit formula for the series $R$.

35 The identity from the last lemma is "divided" by the one from the previous lemma, and then one substitutes Euler's theorem.
} 
- are divisible by 5 . This is exactly the desired assertion that we wanted to prove.

I do not know how you were doing while going through this proof. Every time, I present it during a lecture course, there are always a few students who cannot help but smile when the punch line is revealed.

We come to the Tour de Force! Of course, what Andrew Wiles has accomplished is an incredible tour de force. Since this requires however large chunks of modern number theory and algebra, in a few minutes I can say exactly nothing about it. Therefore, I have chosen a different example for illustration - from my own research area -, namely Doron Zeilberger's (see Figure 5) theorem on alternating sign matrices. First of all, we need to know what an alternating sign matrix is. An alternating sign matrix is a square arrangement of 0 's, 1 's and (-1)'s which satisfies the following rule: if one reads along rows or columns and ignores the 0 's then one reads alternatingly $1,-1,1, \ldots, 1$. In order to avoid any misunderstanding: one starts and ends with a 1. Here is an example of an alternating sign matrix:

$\begin{array}{rrrrrr}0 & 0 & 1 & 0 & 0 & 0 \\ 0 & 1 & -1 & 0 & 1 & 0 \\ 0 & 0 & 1 & 0 & -1 & 1 \\ 1 & 0 & -1 & 1 & 0 & 0 \\ 0 & 0 & 0 & 0 & 1 & 0 \\ 0 & 0 & 1 & 0 & 0 & 0\end{array}$

You may well ask why mathematicians are interested in alternating sign matrices. I cannot say too much here for the sake of brevity. Alternating sign matrices arose originally in a natural fashion around 1980 in work of David Robbins and Howard Rumsey on a generalisation of determinants. Later, it was discovered that the same objects also appear in Theoretical Physics, albeit in different guise, namely as configurations in an - admittedly somewhat simplistic - model for the formation of ice. William Mills, David Robbins and Howard Rumsey asked themselves how many alternating sign matrices there are. More precisely:

How many alternating sign matrices with exactly $n$ rows are there?

Apparently there exists exactly one alternating sign matrix consisting of one row, namely 1.

There are two alternating sign matrices with two rows:

$$
\begin{array}{llll}
1 & 0 & 0 & 1 \\
0 & 1 & 1 & 0
\end{array}
$$

And there are 7 alternating sign matrices with three rows:

$\begin{array}{rrrrrrrrrrrr}1 & 0 & 0 & 1 & 0 & 0 & 0 & 1 & 0 & 0 & 1 & 0 \\ 0 & 1 & 0 & 0 & 0 & 1 & 1 & 0 & 0 & 0 & 0 & 1 \\ 0 & 0 & 1 & 0 & 1 & 0 & 0 & 0 & 1 & 1 & 0 & 0 \\ & 0 & 0 & 1 & 0 & 0 & 1 & 0 & 1 & 0 & \\ & 1 & 0 & 0 & 0 & 1 & 0 & 1 & -1 & 1 & \\ & 0 & 1 & 0 & 1 & 0 & 0 & 0 & 1 & 0 & \end{array}$

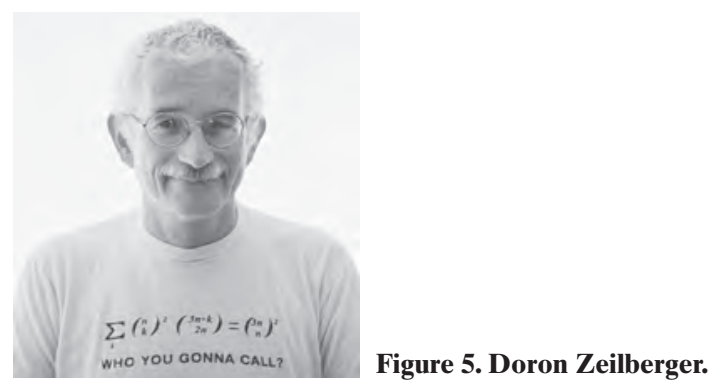

If we denote the number of all alternating sign matrices consisting of exactly $n$ rows by $A(n)$ then the following table

$$
\begin{array}{c|c|c|c|c|c|c}
n & 1 & 2 & 3 & 4 & 5 & 6 \\
\hline A(n) & 1 & 2 & 7 & 42 & 429 & 7436
\end{array}
$$

shows the first values of the sequence. Mills, Robbins and Rumsey studied these numbers carefully and made a remarkable discovery.

\section{Conjecture (Mills, Robbins, Rumsey 1980). We have}

$$
A(n)=\frac{1 ! \cdot 4 ! \cdot 7 ! \cdots(3 n-2) !}{n ! \cdot(n+1) ! \cdot(n+2) ! \cdots \cdot(2 n-1) !},
$$

where $m !=m \cdot(m-1) \cdot(m-2) \cdots \cdot 2 \cdot 1$.

This is extremely surprising. If a mathematician learns about the above question, then the immediate reaction would be that there cannot be any reasonable formula for the number of all alternating sign matrices consisting of exactly $n$ rows. But, no! It seems that there is even an elegant, compact product formula!

But how to prove this? For more than 10 years, mathematicians did not even know how to attack this conjecture. Everybody was therefore very surprised when Doron Zeilberger announced in 1993 that he had found a proof. Along with the announcement, he distributed a 25-page article which contained that proof.

As you know, it is not sufficient to announce that one has proved something. The proof must be written down and submitted for publication, after which the corresponding article is refereed. Zeilberger submitted his article for publication and - you guess it - the referee found gaps in the proof. So, the article went back to Doron Zeilberger with the request to fill the gaps. Zeilberger did some repair work and resubmitted the article, and the referee found new gaps. The article went again back to Zeilberger, he did more modifications, resubmitted, and the article went back and forth in this manner several times, until the referee lost patience. He probably told Zeilberger roughly the following: "Dear Doron! Before you resubmit the article, please do something. Read your proof carefully from the very beginning to the end. If you should not be able to do that, then give the article to a student to check the proof; but, please, do something!"

Doron Zeilberger did do something. First of all, he read and checked his article carefully. Furthermore, he structured the proof completely hierarchically, so that the article could be read "locally"; in the sense that each part 


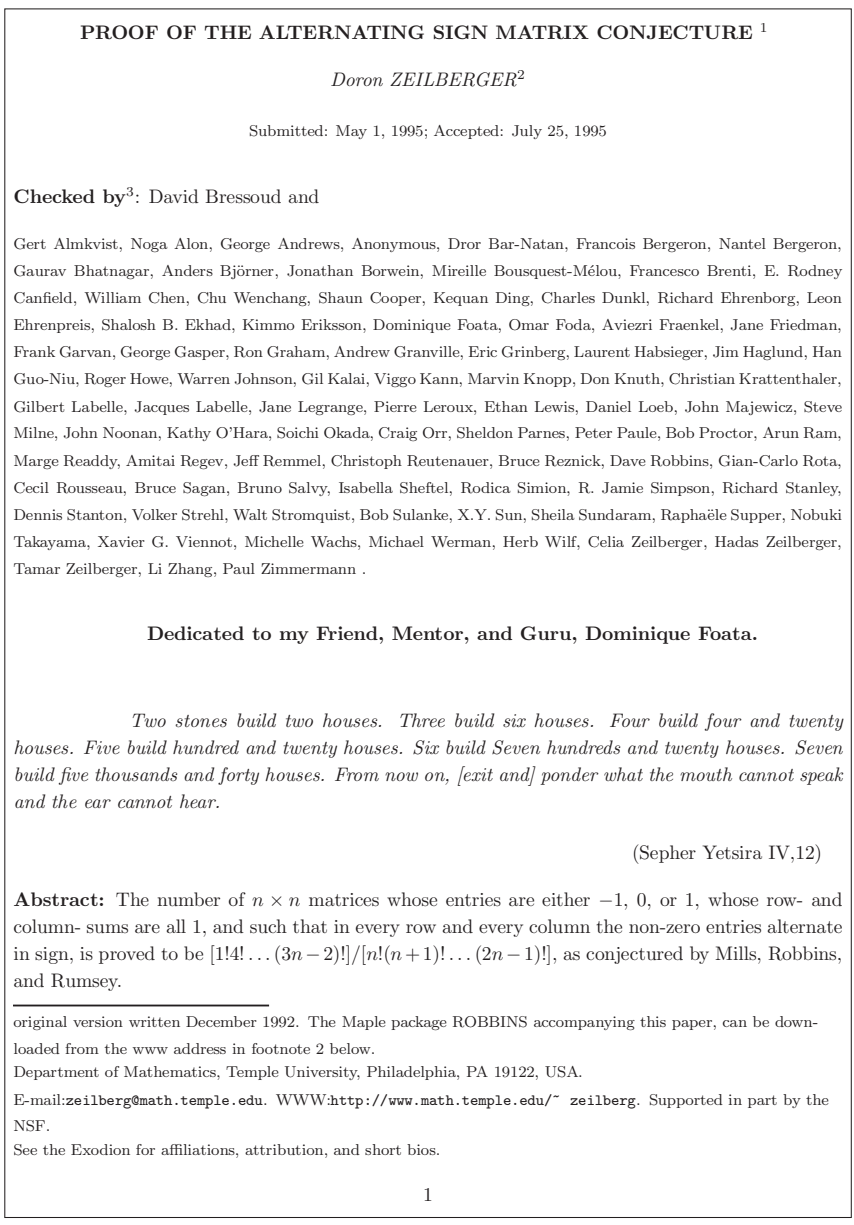

Figure 6.

could be read independently of the rest if one assumed that everything which appeared lower in the hierarchy was correct. Subsequently, he asked about 80 colleagues to check the article. He assigned to each of them 2 to 3 pages, and the task was to check these pages under the assumption that everything which appeared lower in the proof hierarchy was correct. So it happened. A few minor deficiencies were discovered in that way, which could be easily repaired, but nothing dramatic surfaced anymore, and the article was eventually published in $1995 .{ }^{36} \mathrm{In}$ Figure 6, we see the first page of the article. After the title, the aforementioned colleagues (the "checkers", totalling around 80 ) are listed. The article is no longer 25 pages long, but rather 85. As I said, the proof is structured completely hierarchically. The actual main theorem of the article is called Lemma 1 (see Figure 7). This is based on Sublemma 1.1 and Sublemma 1.2. The latter in turn are based on Subsublemma 1.1.1, Subsublemma 1.1.2, ..., Subsublemma 1.2.1, Subsublemma 1.2.2, .., which in turn are based on Subsubsublemma 1.1.1.1, ..., and so forth, up to $\mathrm{Sub}^{6}$, that is, up to Subsubsubsubsubsublemma, one of which we see in Figure 8.

You get the impression: we are talking about a real tour de force. There is one thing, however, that cannot be said about it. One cannot claim that this is a "nice"

${ }^{36}$ Electron. J. Combin. 3 (no. 2, "The Foata Festschrift”) (1996), \#R13, 84 pp.

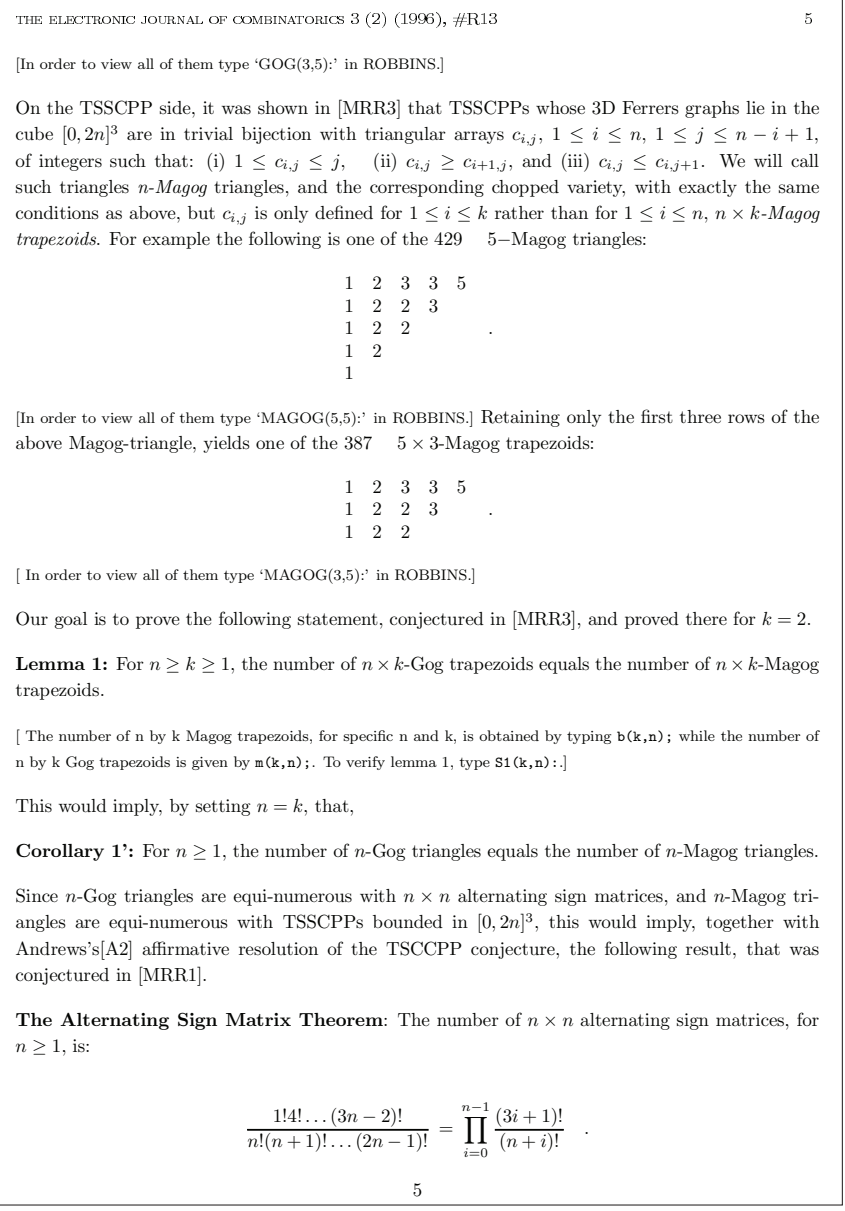

Figure 7.

proof, an elegant proof. In order to defend this, the same Doron Zeilberger - in a different context - went as far as to exclaim: ${ }^{37}$

\section{"Extreme UGLINESS is new BEAUTY!"}

I think we let this stand as it is. The sarcasts among you will say: "Yes, I always had the impression that this is exactly the idea of many modern composers." I would counter that at all times there existed better and worse composers. Once time passes, the worse ones tend to be forgotten, and only the outstanding composers remain. One can verify the latter phenomenon very well if one asks how many composers there were when Beethoven was a celebrity. Answer: innumerably many! If, however, one asks which of those are still known today, which ones are still performed today, then Franz Schubert comes immediately to one's mind (who "ironically" was largely unknown at the time), also Carl Maria von Weber and the Italian opera composers Gioachino Rossini and Gaetano Donizetti. This is it! The same thing will apply for us in 100 or 200 years from now. Most composers will be completely forgotten, and only the outstanding ones will survive. If I may make a personal comment on this

\footnotetext{
${ }^{37}$ Excerpt from a talk at the Third International Conference on "Formal Power Series and Algebraic Combinatorics", Bordeaux, 4 May 1991.
} 


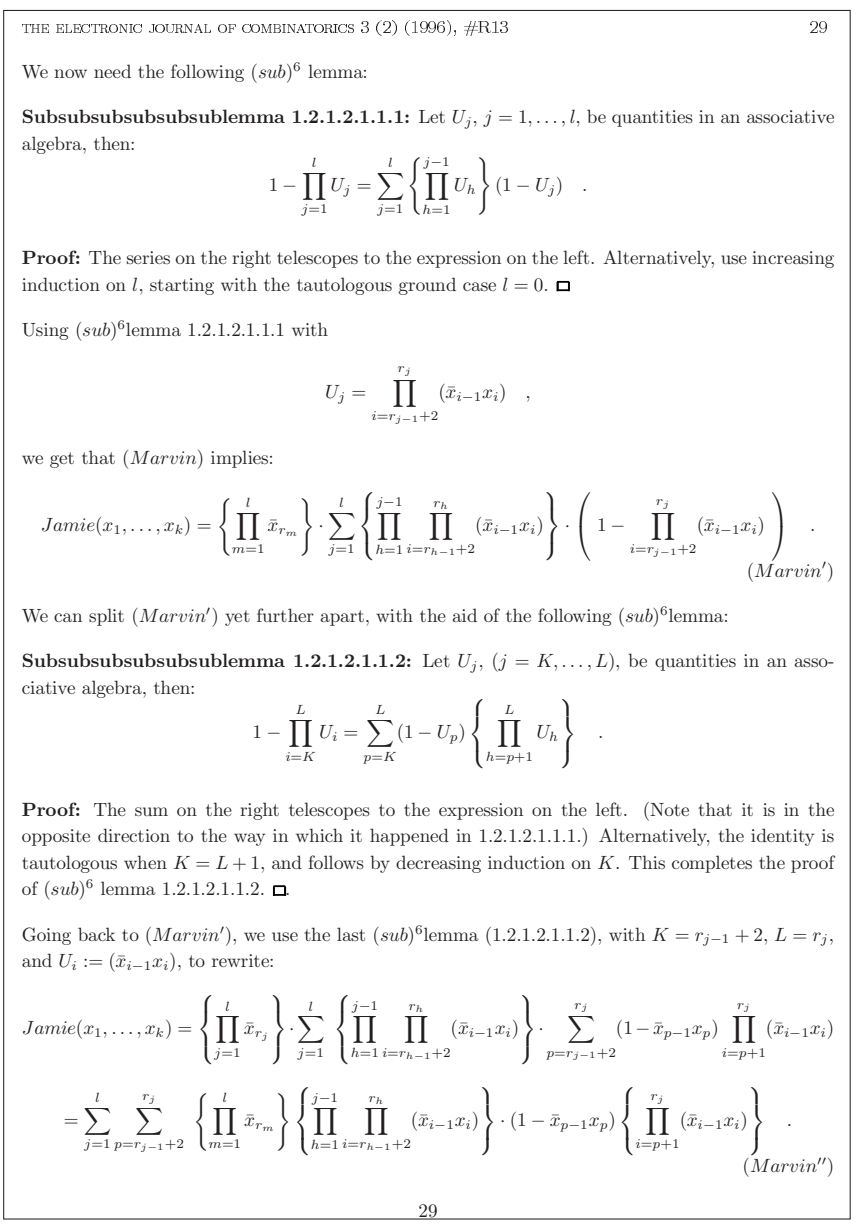

Figure 8.

matter from a local patriotic view: I am convinced that Friedrich Cerha will be one of those composers whose music will still be performed in 100 or 200 years. His powerful, expressive musical language is impressive and also clearly present in pieces which I like less.

Figuratively - not literally - the above statement is essentially what Arnold Schönberg and the composers around him have done. The romantic sound idiom was, after it had also moved into expressionism, exhausted, at its end. No further development was possible. What Arnold Schönberg did then, when he turned to the twelve-tone technique, was radically rupture all common habits and rules. He based his music on a completely new foundation, with completely new rules. He believed -hoped - that in this way a new musical aesthetic would emerge. I, personally, regard this experiment as a failure. As I already said at a different occasion: I understand that a genius such as Arnold Schönberg tried this path, but I do not understand why he did not find an escape from this - as I see it - dead end of musical history. (That Schönberg was a musical genius is single-handedly proved by his string sextet "Verklärte Nacht". ${ }^{38}$ This is such an incredibly touching and moving, and at the same time complex piece as only a genius can write. To me, it belongs to the greatest compositions ever.)

38 "Transfigured Night".

\section{Brains in mathematics}

You may argue that there is little to say on this topic. Obviously, reason and thought are the essentials in mathematics. You are right, of course. Hence, we may consider this topic as checked...

\section{Brains in Music}

This is again an entire topic in itself. There is the widespread naive idea, concerning pianists, that a pianist must practise diligently, and in the evening of the concert he storms onto the stage, sits down at the piano, and cuts loose. Yes, this is a possibility, but this is not how it works. The audience will notice ${ }^{39}$ that not much thought went into that interpretation. It will not really make sense, it will remain inconclusive. Indeed, if one looks at the great pianists, one will notice that emotion and thought always go together - form a symbiosis - certainly with different weighting in each individual case. The prototypical example is Alfred Brendel, where it is amply established by his books just how much thought went into his interpretations, and where simply watching him play was sufficient to understand what a sensitive and emotional artist he was.

Concerning composers, there is a similar widespread conception that it is most important to have good melodic ideas. Everything else just works by itself. In response to this, I can only say that at all times there are and have been many more composers with good melodic ideas than good (or even outstanding) composers. The great art is in bringing to bear the melodic ideas, the themes, and in building, forming, and developing the pieces. Here too the following applies: if one looks at the great composers, then emotion and thought always go hand in hand. For composers such as Bach, Beethoven, or Brahms, this is obvious anyway. However, it also applies to composers who are not really under suspicion of having approached composition in a particularly intellectual manner. In this latter category, I would see Franz Schubert, Anton Bruckner, or also Modest Mussorgsky. One will be surprised how much thought went into the compositions of even these composers. For Mussorgsky, it suffices to consider his "Pictures at an Exhibition," how the promenades keep the work artfully together, how the theme of the last picture, the "Great Gate of Kiev" is extracted from the theme of the promenade, which is itself formed in a self-referential way. Bruckner's scores are highly complex anyway. Even in the work of Schubert the role of reason and thought is much bigger than one would commonly believe. I want to give a glimpse of an idea here. The example I have chosen is the Great Sonata in A major, D 959, from Schubert's last year of life. This sonata has four movements. A broad first movement, whose proud opening theme is the following:

\footnotetext{
${ }^{39}$ Singular exception is presumably Martha Argerich, whose interpretations do not seem to be very reflective. Instead, she proceeds rather spontaneously when playing. I have the greatest respect for Martha Argerich. Her musicality is marvellous. I did however also listen to pieces played by her which, due to her spontaneous approach, - so-to-speak - disintegrated under her fingers...
} 


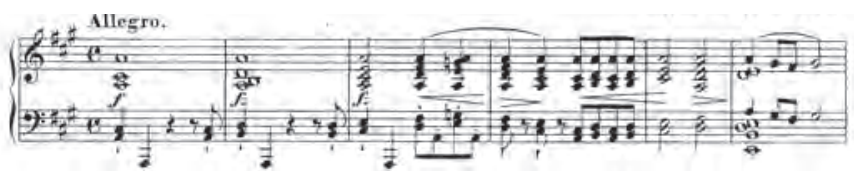

We already know the heartbreakingly sad theme of the second movement:

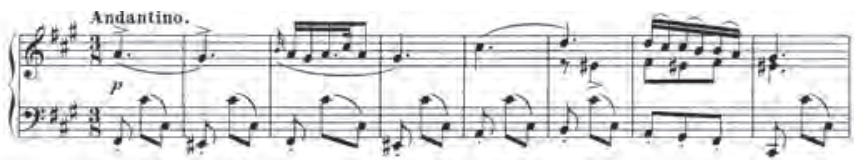

There follows a playful Scherzo, which also contains Ländler ${ }^{40}$ elements:

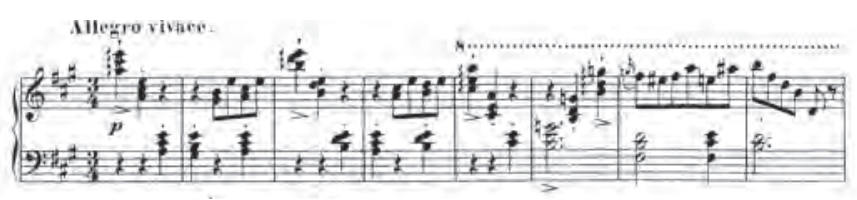

The concluding melodious Rondo begins as follows:

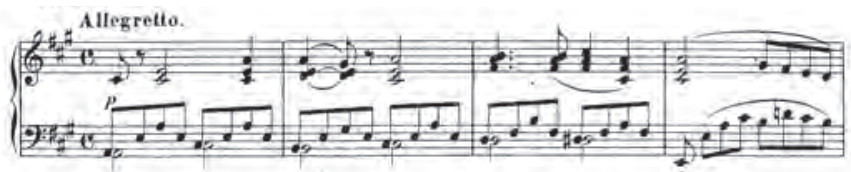

You will not have noticed, but maybe you sensed it: these four themes, so different in character, are bound together by a hidden brace. This is what I now want to expose.

If one looks at the opening theme of the first movement more closely, then one recognises that (in the upper voice) the note $a$ is at first repeated several times, before it is "resolved" to a $g$ sharp in the end, which is also ornamented by an $f$ sharp. Thus, if one reduces the theme to its nucleus then it becomes clear that we are talking of a largely blown up suspension $a-g$ sharp:

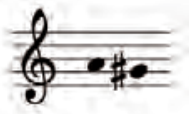

How does the second movement begin? The answer is: $a-g$ sharp. How does the Scherzo fit in? This is more hidden. Here, one must look at the lower voice in order to discover $a-g$ sharp again! The theme of the last movement even contains the suspension $a-g$ sharp twice (namely in the second and in the fourth bar, both times in the upper voice).

Sure, these fine points are not consciously noticed by the listener, nonetheless, they do have an unconscious effect. In our concrete case, they contribute to the great unity of the sonata. It is, among other things, these details that make the difference between a masterpiece and compositions of average quality.

${ }^{40}$ A "Ländler" is a rural dance in Austria. The German translation of "rural" is "ländlich".

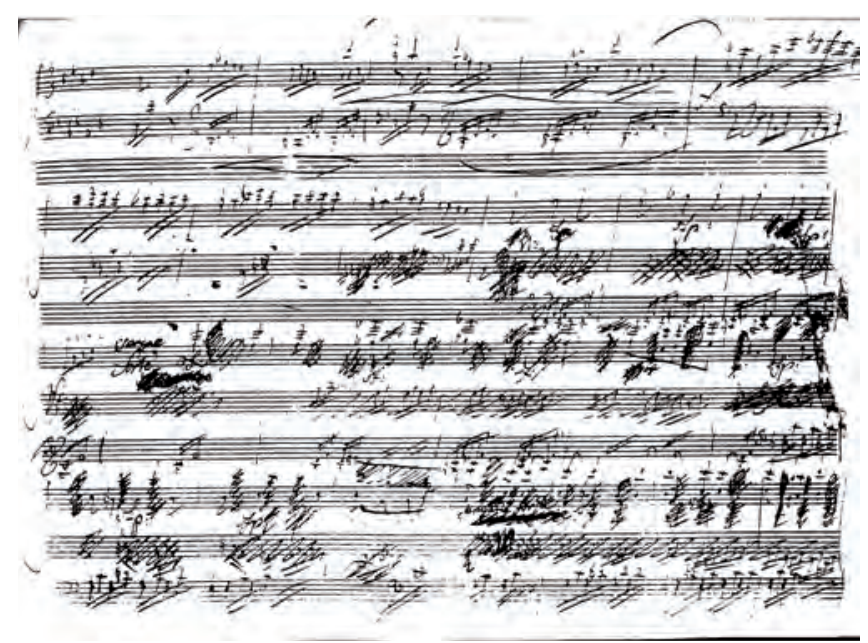

Figure 9.

\section{Differences between mathematics and music}

So far, I have talked a lot about parallels between mathematics and music. I should perhaps also address the differences between them. In short, there are many. Here, I only want to work out the most significant difference.

This begins with another parallel. When a composer has the great inspiration and a composition materialises in his/her head, then it must now be written down in order to be performed. This may then look as in Figure 9.

When a mathematician has a brilliant idea and proves a great new theorem, then it must now be written down in order for others to be able to study it. This may then look as in Figure 10.

If somebody cannot read scores and also does not understand anything of mathematics: I would say, there is no discernible difference between the two; each is as incomprehensible as the other...

Let us return to the score. It must now be brought to life. In the case of the "Appassionata", we need a pianist. This pianist must carefully study and practise the piece, and then perform it. And this performance - this is it! This is the complete composition! Nothing was added, nothing was omitted (if we neglect that the pianist stumbles possibly here and there...). And everybody can sit down and listen to it. No prior education is required for that. If one has an affinity with the musical language of Beethoven, then one will be captivated by the dark, tense atmosphere of the Appassionata.

Now you may object: but at the university, in the mathematics courses, there mathematics is "performed." Somehow, yes. However, this is actually different. You cannot simply sit down in a course and delight in the various qualities of the "performed" mathematics. Depending on how advanced a course is, it requires more or less prior knowledge from the listener in order to understand at all what is being discussed. (Even the courses in the first semester require certain prior knowledge, without which it is not advisable to attend such a course. Unfortunately, every year there arrive more freshmen than we would like for whom this is apparently not so clear...). In the courses, it is common practise to build on this prior knowledge, and to not repeat what is (should be) already 


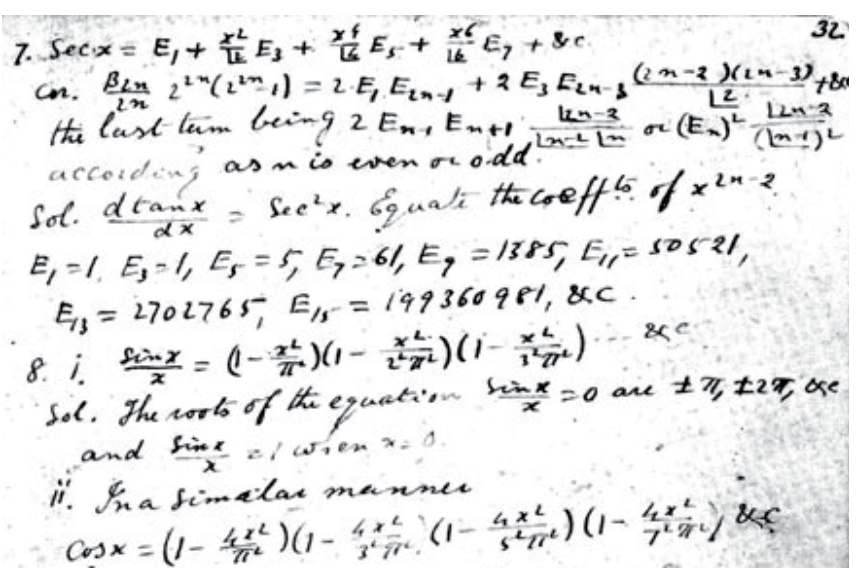

Figure 10.

known. Moreover, for conclusions which are somehow "obvious", it is left to the listener to fill in the details. In this sense, also in courses at the university there is no (complete) performance of mathematics.

You will insist: okay, but at mathematics conferences, there mathematicians present their latest results in front of their colleagues, there mathematics is "performed"! The former is certainly correct, but here as well there is no "performance" of mathematics which takes place in the same sense as music is performed. At a conference, you may have maybe 30 minutes, maybe an hour to present your latest result. What is presented the lecturer has thought about for weeks, months, sometimes years. This cannot be presented in all detail within 30 minutes or an hour. What one therefore does is explain the assertion of the newest theorem, and subsequently indicate which ideas go into the proof. If a listener wants to completely work through the proof, respectively wants to completely check the proof in all detail, then (s)he must study the article in which this proof is written down. So, also here, there is no "performance" of mathematics.

This has a very lamentable consequence for mathematicians: I would say that - very roughly estimated - 90 percent of the population are amenable to music. If one subtracts popular music, then there remain still - conservatively estimated -10 percent who are addressable by - let me say - expressive music. ${ }^{41}$

How are matters with mathematics? I would formulate it as follows. You may perhaps remember from high school that mathematicians have a special symbol for infinitely small quantities: the $\varepsilon$ ! So, I would say that roughly $-\varepsilon$ percent of the population are amenable to the manifold qualities of the science of mathematics.

This is very grievous for mathematicians. Frequently, mathematicians are reproached for not stepping out of their ivory tower and not explaining a wide audience what they are doing. As a matter of fact, mathematicians would love to do exactly that: with great excitement, they would present and explain their newest theorem - their

\footnotetext{
${ }^{41}$ I never knew what to do with the labels "classical music" and "light music".
}

newest composition, so to speak - in front of a wide audience. However, because of the earlier described difficulties, it is impossible! In order to avoid any misunderstanding: I am not saying that one should not talk about mathematics. On the contrary! What I am doing here is, in a sense, also to talk about mathematics. However, if it comes to current research, then one will have to take recourse to metaphors, then one will only be able to vaguely indicate what is really going on. As I said: the performance of mathematics does not exist, and thus a mathematician will never be able to convey to a wide audience what (s)he experiences when (s)he deals with mathematical problems and their solutions. Here, mathematicians are always at a disadvantage when compared to musicians - and to researchers in other disciplines; music speaks directly to the listener, no "translation", no further explanation is necessary, and this is in sharp contrast to mathematics. ${ }^{42}$

\section{Personal notes}

What do mathematics and music mean to me? A lot, obviously. First of all, there is the inexplicable, magical component. If I am asked why I went for music and mathematics: I do not know. I remember very well that, as a 6-7-year old, I used to sing along with great passion. Why? I do not know. I also remember very well that, as a 13-14-year old, I was burningly interested in how big the probability is that, by throwing a given number of dice, one scores a certain total; so, for example, how likely it is to score 36 by throwing 10 dice. I computed (by hand) long tables, and I studied the numbers in these tables. After work of several years, I was indeed able to find a formula for this probability. Obviously, at the time, I did not have the slightest idea how to prove it. ${ }^{43}$ Why was I so fascinated by this? I do not know.

What fascinates me today in mathematics and music? When it comes to mathematics, there is for one the challenge to "crack" open problems as they constantly arise in physics, in computer science, and also in mathematics itself. Interestingly, in my research work, in order to solve a problem, I frequently study long tables (nowadays computed by using a computer, of course), subsequently I try to guess a mathematical formula for the numbers in these tables (also partially with the help of a computer), and then - if successful - try to prove this newly discov-

\footnotetext{
${ }^{42}$ Consequently, Cédric Villani, in his remarkable and controversial book "Théorème vivant" (in the English translation: "Birth of a Theorem") - in which he describes how the proof of the theorem emerged that significantly contributed to the award of the Fields Medal to him in 2010 - does not even try to explain the mathematics behind, but on the contrary intentionally remains often incomprehensible even to mathematicians who are not experts in the field of partial differential equations, in order to entirely concentrate on the emotional side of the involvement with mathematics. Villani is highly successful doing this, but - seen plainly - he does not talk about mathematics.

${ }^{43}$ Today I know that this formula can be easily proved with the help of generating functions or with the help of the principle of inclusion-exclusion.
} 
ered conjecture. Moreover, I am of course fascinated by searching and discovering hidden structures and connections behind the problems and their solutions. Clearly, the aesthetic component in mathematics plays a big role for me as well.

Also in music, I am fascinated by fathoming new territory. It is extremely interesting to take a new ${ }^{44}$ piece, and now start working on it. As we already discussed: a score must be brought to life. When one starts studying a piece, one often does not know which are the important points within it, how to understand the structure of the piece, and how the piece should develop when played. I remember very well the situation when I, together with my trio partners, started to prepare the third movement of Mozart's piano trio in C major, KV 548, for an encore of a concert evening. Each of us had - individually -prepared and practised one's own part, but the first "reading" of the movement ended up in a complete disaster: nothing made any sense at all. The violinist immediately pled that we choose a different piece as an encore ... I insisted to give the piece a chance. So, we started to work on it, and, lo and behold, this "ugly duckling" slowly transformed itself into a lively, witty piece of music, which was a great pleasure to play for all of us.

Another important point is that, once one has worked out an interpretation of a piece, to present this - own - view of the composition in front of an audience. Each time, this is a tremendously interesting and exciting experience. One never knows in advance how this is going to develop, but the more this is tantalising, and the more this can be enriching.

In any case, for me, mathematics and music always have been two very different things that complement each other. And it is exactly this complementary aspect that I have always found so interesting and appealing. It is perhaps unhealthy to become obsessed with just one matter. When I am trying to solve a mathematical problem and I arrive at a dead end where I do not know how to proceed, then I may sit down at the piano and concentrate on something completely different, and in this way clear my mind. Maybe upon returning to the mathematical problem, I will have a new, fresh view of things, which allows me to progress again.

\footnotetext{
${ }^{44}$ Meaning: "not yet studied".

45 The citation is from the talk "Ten Lessons I wish I had been Taught", which Rota delivered on 20 April 1996 at the occasion of a birthday conference in his honour at the Massachusetts Institute of Technology in Boston. It can be read in the Notices of the American Mathematical Society, vol. 44, Nr. 1, 1997, pp. 22-25 (see http://www.ams.org/notices/199701/ comm-rota.pdf).

${ }^{46}$ In danger of exhibiting a certain bias, Alfred Brendel's wonderfully balanced view can be enjoyed on YouTube in two parts: http://www.youtube.com/watch? $\mathrm{v}=\mathrm{PlV}-\mathrm{ksfS} 7 \mathrm{~F} 8$, http:// www.youtube.com/watch? $\mathrm{v}=\mathrm{QxBGG} 74 \mathrm{ztVo}$.

${ }^{47}$ An old concert recording of this piece with the author himself at the piano can be found at http://www.mat.univie. ac.at/ kratt/klavier/brahms119-1.html.
}

\section{Conclusion}

Thus, I arrive at the end of my discourse on "Mathematics AND Music?". To tell you a secret: it is absolutely allowed to remain largely incomprehensible during a mathematical talk; there is but one condition (in the words of the influential Italian/American mathematician Gian-Carlo Rota as a postulation of the audience to the speaker $\left.{ }^{45}\right)$ :

\section{"Give us something to take home!"}

In this sense, I hope that I was not too incomprehensible, and that there was something for you to take home. On this point, I have one thing further to offer, a piece of music at the end. Obviously, it must suit our motto "Soul AND Brains". Clearly, one could find many natural candidates, for example, in the work of Johann Sebastian Bach, or of Ludwig van Beethoven. However, this would be too simple, too conventional. Instead, I chose the Sonata Opus 1 by Alban Berg. He wrote this sonata at 23 years of age. It is, in a sense, the final "paper" of his music studies, which he mainly undertook under Arnold Schönberg. If you wish, it is Alban Berg's musical "thesis," in order to stress another analogue with mathematics. It fits excellently with our motto "Soul AND Brains". I would say that the musical language of this sonata can be classified as expressionistic. It is thus highly emotional. On the other hand, it is an incredibly dense musical construction, in which the complete piece of approximately 10 minutes is extracted from one nucleus - namely the theme at the beginning.

Enough of explanations. I will now play the Sonata Opus 1 by Alban Berg. I shall directly adjoin a prayer by Johannes Brahms. "Intermezzo" is the original title by Brahms, from the last piano pieces that he wrote. I have always liked to do this, since, first of all, the two pieces fit so well together, and, second, if one listens, then one understands where the musical language of Berg comes from.

\section{$\langle\text { Alban Berg (1885-1935): Sonata op. } 1\rangle^{46}$ \\ 〈Johannes Brahms (1833-1897): Intermezzo in b minor, op. 119/1 $\rangle^{47}$}

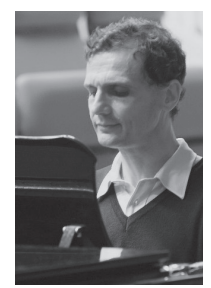

Christian Krattenthaler studied mathematics at the University of Vienna and piano at the Vienna University of Music and Performing Arts. After finishing his studies (mathematics 1984, piano 1986), he pursued both careers (lecturer at the University of Vienna and concert pianist) for a while. He terminated his activities as a concert pianist in 1991 because of an incurable ailment of both hands. After holding a position as a professor at the Universite "Claude Bernard" Lyon-I from 2002 to 2005, he was appointed as a professor of discrete mathematics at the University of Vienna. For his scientific achievements, he was awarded the Wittgenstein-Prize in 2007. 